\title{
SOME PROBLEMS OF THE ANTARCTIC MASS BUDGET
}

THE second paper of the third session was read by Mr. J. T. Hollin, who started by pointing out that at least four of the recently published budgets (Wexler, I 96I) arrive at the conclusion that there is a large positive budget-that the ice sheet is gaining roughly twice as much by accumulation as it loses by ablation. If this is true then certain consequences should follow: (i) sea-level should be falling, and it does not appear to be doing so at the right rate; (ii) the glaciers in the Antarctic should be advancing, and such evidence as there is suggests that, if anything, there has been a slight retreat; (iii) there should be a positive isostatic anomaly, whereas both American and Soviet work seem to deny this (see Hollin, 1962, p. 189). All this suggests that if the budget is positive it has not been so for very long, and the ice sheet has not yet responded at its edges. This would imply a fairly recent increase in accumulation or decrease in ablation. However the I.G.Y. drilling projects show that there has been no major change in accumulation at S-2 near "Wilkes Station" since A.D. I 783 (Cameron and others, I959), while at "Byrd Station" the accumulation has actually decreased slightly since A.D. I547 (Bender and Gow, I96I) and at the South Pole there has been no major change since A.D. I530 except for a minor increase with a maximum in the I920's (Giovinetto, I $960[\mathrm{a}],[\mathrm{b}])$. Thus if there has been an accumulation increase, it must have occurred over 400 yr. ago. However in the northern hemisphere there have been few fluctuations greater than those of the last $400 \mathrm{yr}$. for about $10,000 \mathrm{yr}$, , and so it is only over times of that order that we could expect a major change in the Antarctic accumulation of the type contemplated by Meinardus (reviewed by Simpson, r940).

However, the further one pushes this date back, the harder it is to account for the lack of any glaciological evidence of advance at the coast. Nye (1959, p. 500-02) has estimated the time constant for Antarctica to be about 5,ooo yr., so some response at the edge would be expected from a change in budget anything like $10,000 \mathrm{yr}$. ago. There only remains one possibility, that the ice sheet is undergoing a thermal build-up of the type suggested by Robin (1955). If this is so, then a large part of the Antarctic Ice Sheet must be frozen at the base, and when geothermal and frictional heat warms up the base, a rapid outflow will begin and mass balance will be restored. However, it is difficult to envisage this mechanism occurring over the whole ice sheet at once. It is more likely to operate in more or less random sequence in the various drainage basins. Of course it is possible that the horizontal forces produced by the release of one such basin might trigger its neighbours, and this needs further study, but no such triggering occurred at Brasvellbreen, Sørfonna, Nordaustlandet, where a whole sector of a roughly circular ice cap advanced catastrophically in 1938, apparently without affecting neighbouring sectors.

These considerations suggest that the positive mass balance is not real, and that further measurements are needed to make certain what the balance is. To do this it might be more efficient to start by making budget studies over a particular, relatively small drainage basin, and then to work towards larger and larger basins, realizing that each has its own response time to perturbations. The basins, defined by surface slope measurements, could be chosen for logistic convenience. Secondly, because the budgets of the grounded ice sheet and of the floating ice shelves are really quite separate, the one linked to atmospheric and the other to oceanic events including the very awkward calving term, it may be more convenient to terminate the budget at the grounding line. Of course the two budgets share a flow term, and it may be convenient in the field to work on the two together. Finally it should be remembered that our accumulation measurements may be biassed. Bases tend to be put where winds are least severe, and as a result the effect of katabatic winds in removing accumulation may pass unnoticed. Pit measurements may also be unreliable, not only because horizons are difficult to identify, but also because in some places accumulation occurs only in certain years. Measurements made with long stakes are much more reliable. When such measurements 
are available, and when we know the depth of ice by gravity and seismic measurements and ice flow velocities by tellurometry, etc., we shall be in a better position to see the true state of the Antarctic mass balance.

\section{REFERENGES}

Bender, J. A., and Gow, A. J. 1961. Deep drilling in Antarctica. Union Géodésique et Géophysique Internationale. Association Internationale d'Hydrologie Scientifique. Assemblée générale de Helsinki, 25-7-6-8 ig6o. Colloque sur la glaciologie antarctique, p. $132-4 \mathrm{I}$.

Cameron, R. L., and others. 1959. Wilkes Station glaciological data 1957-1958, by R. L. Cameron, O. Løken and J. R. T. Molholm. Ohio State University Research Foundation. Report 825-I-Part III.

Giovinetto, M. B. I96o[a]. South Pole glaciological data 1958. Ohio State University Research Foundation. Report 825-2-Part IV.

Giovinetto, M. B. $1960[\mathrm{~b}]$. Glaciological studies at the South Pole Station. Union Géodésique et Géophysique Internationale. Monographie No. 5, p. 64. [Abstract of paper presented at Simposio Antártico de Buenos Aires, November 1959.]

Hollin, J. T. 1962. On the glacial history of Antarctica. Journal of Glaciology, Vol. 4, No. 32, p. $173-95$.

Nye, J. F. 1959. The motion of ice sheets and glaciers. Fournal of Glaciology, Vol. 3, No. 26, p. 493-507.

Robin, G. de Q. I 955. Ice movement and temperature distribution in glaciers and ice sheets. Fournal of Glaciology, Vol. 2, No. 18, p. 523-32.

Simpson, Sir G. C. 1940. Possible causes of change in climate and their limitations. Proceedings of the Linnean Society of London, 152nd Session, Pt. 2, p. 190-2 19.

Wexler, H. 1961. Ice budgets for Antarctica and changes in sea-level. Journal of Glaciology, Vol. 3, No. 29, p. $867-72$.

\section{DISGUSSION OF MR. J. T. HOLLIN'S PAPER}

Dr. J. F. Nye: You make the point that you cannot reconcile an accumulation which has been constant for, say, I0,000 yr. with a positive mass balance now. In the course of this you quote a figure of 5,00o yr. from my work. I would not want that to be taken too seriously. First, it is, mathematically, not the total time taken for readjustment, it is more a sort of halflife. I would expect things to go on for times of I0,000 to 20,000 yr. And then, quite apart from that there is what I might call the "theoretical error" that might change the constant by a factor of two to four-the constant might be ro,ooo yr. and the ice sheet might still be reacting, building up.

Mr. Hollin: Yes, but if so it is rather surprising that it is all building up in phase.

DR. Nye: The small glaciers near the margin might already have adjusted themselves, so that if you look at the end of a glacier you do not see changes any more, but the ice sheet itself is such a big thing, it might not have reacted yet.

Mr. Hollin: Let us do a rough calculation; suppose the accumulation has doubled from, say, $7 \mathrm{~g} . / \mathrm{cm}^{2} \mathrm{yr}$. to $14 \mathrm{~g} . / \mathrm{cm}^{2} \mathrm{yr}$., then, at a point where the thickness was previously 2,000 m., the new thickness (since the width of the ice sheet is essentially fixed by sea-level (Hollin, I962)) will be (Nye, I 959, p. 498) $2,000 \times 2^{\frac{1}{6}}=2,25^{\circ} \mathrm{m}$. This build-up could take at most 3,600 yr. If it took longer some of the material would have to escape sideways and the budget would cease to be out of balance. Also, in reality, some of the increased accumulation will be carried to the edge with no delay at a velocity which cannot be less than the old steady-state velocity. This is what Dr. Nye has estimated as dying away to $\mathrm{r} / \mathrm{e}$ of its value in 5 , $000 \mathrm{yr}$. In practice such perturbations must be concentrated in the marginal part of the ice sheet, where the ice circulation is most rapid, and the time constant for such areas is such that a large part of any accumulation increase must be removed horizontally in hundreds rather than thousands of years. 
DR. NYE: One has to distinguish between the edge where you have glaciers finishing on land and the edge where there is ice going off into the sea. I understand that the glaciers look pretty stationary, but of course we do not know whether the rate of calving into the sea has increased or decreased.

DR. J. W. GLEN : Surely it does not matter what the velocity with which ice is coming out by calving is, provided it has been assessed correctly. If we have a positive mass balance in Antarctica, then either the middle is getting thicker and it has not yet affected the edges, or the edges are pushing out. This is just as true of the part which is calving as anywhere else, and there is no evidence over admittedly a racher short period of time that the calving glaciers have pushed out markedly.

DR. H. Lister: There is one little bit of evidence that $I$ feel is fairly reliable, and that is that the snow surface across Antarctica has the most minute grains from the surface to some metres down. There is very little change and the only way we pick out the annual layers is by trying to understand the depth hoar which is dominant in autumn. Now if the Antarctic is not receiving a reasonably adequate layer, the surface grains would be much bigger, they would get that savage temperature gradient through them each spring and each autumn which I think produces the big hoar crystals, and if we do not get large grains most of the way across the continent, then surely we must be having some centimetres of deposit added each year, and even this "thin" blanket cannot be got rid of by the rate of flow according to our existing knowledge, but, agreed, our existing knowledge is inadequate.

Mr. Hollin: Yes, this is one line of evidence, but it is based on limited information, particularly about ablation of course, but I think these other lines of investigation, sea-level, isostasy, glacial geology, and the accumulation records are in their ways just as good evidence.

DR. G. DE Q. RobIN: I would like to reinforce what Mr. Hollin has said about the typicality of accumulation measurements. The same certainly applies with regard to the major ice streams. Dr. C. W. M. Swithinbank is making a major investigation of several major ice streams. We know nothing about the volume discharge of the Lambert Glacier for example and yet this is draining an enormous basin. Most of the figures of discharge are for relatively small glaciers. We do not know our major loss terms as yet.

Mr. J. MACDowall: I was interested in the suggestion that some stations may have nonrepresentative accumulation measurements. Obviously this is a possibility; people are likely to try more sheltered areas for a base. However the implications of this on your measurements depend very much on what happens to snow when the wind is blowing. We need to know whether this snow subsequently falls elsewhere in the vicinity.

Mr. Hollin: I simply wanted to draw attention to factors that might be influencing us to a heavy budget. I have a photograph from "Wilkes Station" at the end of the accumulation season. One half of the field of view is beautifully white, while the other half, the Vanderford and John Quincy Adams Glaciers area, is blue because there has been no real accumulation there. 